\title{
PEMANFAATAN LIMBAH KULIT BUAH PISANG KEPOK (Musa paradisiaca) SEBAGAI BIOSORBEN ZAT WARNA RHODAMIN B
}

\section{[The Utilization of Banana Peels (Musa paradisiaca) as Biosorbent of Rhodamine B]}

\author{
Musafira $^{1}$, Nurfitrah. M. Adam ${ }^{2^{\star}}$, Dwi Juli Puspitasari ${ }^{2}$ \\ 1) Fakultas MIPA Universitas Sulawesi Barat, Mejene \\ 2) Jurusan Kimia, Fakultas MIPA, Universitas Tadulako, Palu \\ J. Soekarno Hatta Km.9, Kampus Bumi Tadulako Tondo Palu, Telp. 0451- 422611 \\ *)Coresponding author: adamvhyta@gmail.com
}

Diterima 6 Desember 2019, Disetujui 28 Desember 2019

\begin{abstract}
The investigation about the utilization of Banana peel (Musa paradisiaca) as biosorbent Rhodamine B dye has been done The purpose of this study was to determine the maximum contact time and to determine the adsorption capacity of kepok banana peel. Completely randomized design (CRD) was used in this research with two variables (the contact time and Rhodamine B concentration. Both variables were done in five levels i.e 10, 30, 60, 90, and $120 \mathrm{~min}$ and 2, 4, 6, 8 and $10 \mathrm{ppm}$ respectively. The result showed that the maximum concentration of banana peel in adsorbing Rhodamine B was $6 \mathrm{ppm}$ with 120 of contact time, and Rhodamine B adsorption capacity was $4.55 \mathrm{mg} / \mathrm{g}$.
\end{abstract}

Keywords: Banana peel, Rhodamine B, biosorbent

\begin{abstract}
ABSTRAK
Telah dilakukan penelitian tentang Pemanfaatan Limbah Kulit Pisang Kepok (Musa Paradisiaca.) sebagai biosorben zat warna Rhodamin B. Yang bertujuan untuk mengetahui waktu kontak maksimum dan menentukan kapasitas adsorpsi kulit pisang kepok. Penelitian ini menggunakan Rancangan Acak Lengkap (RAL) dengan dua variabel yaitu waktu kontak yang terdiri atas 5 taraf $(10,30,60,90$, dan 120 menit) dan konsentrasi Rhodamin B yang terdiri dari 5 taraf $(2,4,6$, 8, dan $10 \mathrm{ppm}$ ). Hasil penelitian diperoleh bahwa konsentrasi maksimum kulit pisang dalam menyerap Rhodamin B adalah pada 6 ppm dengan waktu kontak 120 menit, dan kapasitas adsorpsi Rhodamin B sebesar $4,55 \mathrm{mg} / \mathrm{g}$.
\end{abstract}

Kata Kunci : Kulit pisang kepok, Rhodamin B, biosorben 


\section{LATAR BELAKANG}

Pencemaran lingkungan yang diakibatkan oleh limbah zat warna akhirakhir ini terus meningkat. $\mathrm{Hal}$ ini disebabkan industri tekstil yang tidak memiliki pengolahan limbah dengan baik. Limbah zat warna yang dihasilkan dari industri tekstil umumnya merupakan senyawa organik non-biodegradable, yang dapat menyebabkan pencemaran lingkungan terutama lingkungan perairan. Karena pada proses pencelupan hanya sebagian zat warna yang akan terserap oleh bahan tekstil dan sisanya (2-50\%) akan berada dalam proses pembilas (efluen) tekstil, sehingga apabila konsentrasinya cukup besar, maka dapat mencemari lingkungan. Keberadaannya dilingkungan dapat menjadi sumber penyakit karena bersifat karsinogenik dan mutagenik (Wijaya et al., 2006). Salah satu zat warna yang digunakan dalam industri tekstil adalah Rhodamin B.

Rhodamin B merupakan zat warna sintesis yang sering digunakan khususnya dalam industri batik. Rhodamin $B$ berbentuk serbuk Kristal, tidak berbau, berwarna kehijauan, berwarna merah keunguan pada konsentrasi tinggi dan berwarna merah terang pada konsentrasi rendah. Zat warna Rhodamin $B$ merupakan zat warna dasar yang penting dalam proses pewarnaan pada industri tekstil dan kertas. Rhodamin B sangat berbahaya karena dapat menyebabkan iritasi dan kanker pada manusia. Dalam konsentrasi tinggi efek kronis Rhodamin B dapat menyebabkan kerusakan pada hati (Syah, 2005).

Zat warna sintetis dalam limbah industri sangat beracun bagi kehidupan di air. Oleh karena itu diperlukan suatu upaya untuk mengurangi dampak pencemaran dari zat warna tersebut. Salah satu upaya untuk mengurangi pencemaran adalah adsorpsi menggunakan adsorben. Pemanfaatan limbah yang berasal dari pertanian merupakan salah satu upaya dalam mengatasi permasalahan pencemaran ini. Limbah pertanian yang merupakan tongkol jagung, tempurung kelapa, ampas tebu dan kulit buah seperti kulit jeruk dan kulit pisang dapat dijadikan adsorben. Kulit pisang yang merupakan limbah pertanian yang selama ini hanya dibuang begitu saja ternyata mampu digunakan sebagai adsorben dalam menghilangkan zat warna reaktif seperti Sunzol Yellow GR dalam perairan (Khan et al., 2011).

Kulit pisang mengandung sejumlah nitrogen, sulfur dan komponen organik seperti asam karboksilat, selulosa, hemiselulosa, pigmen klorofil dan zat pektin yang mengandung asam galakturonat, arabinosa, galaktosa dan rhamnosa. Asam galakturonat diduga berperan sebagai senyawa yang dapat mengadsorpsi zat warna dan merupakan gugus fungsi gula karboksil (Pankaj et al., 2012).

Penelitian dengan menggunakan limbah kulit pisang kepok sebagai adsorben sebelumnya telah dilakukan 
oleh Pratiwi (2014), adsorben dengan menggunakan kulit pisang kepok memiliki kapasitas adsorpsi yang tinggi terhadap logam $\mathrm{Hg}$ dengan presentase penjerapan 99,25\%, waktu kontak 30 menit, dan konsentrasi 60 ppm. Penelitian dengan menggunakan limbah kulit pisang kepok sebagai adsorben juga telah dilakukan oleh Dyah et al., (2015) yang menggunakan kulit pisang sebagai adsorben zat warna Methylene Blue dan diperoleh kapasitas adsorpsi Methylene Blue oleh kulit pisang sebesar 2,85 mg/g. Penyerapan tersebut disebabkan karena kulit pisang mengandung polisakarida. Polisakarida dari kulit pisang ini dapat dijadikan adsorben baik penyerap zat warna maupun untuk penyerap logam (Annadurai, 2002).

Mengacu pada penelitian tersebut maka diharapkan pada penelitian ini kulit pisang kepok dapat juga digunakan untuk menyerap zat warna lain khususnya Rhodamin B.

\section{METODE PENELITIAN}

\section{Bahan dan Peralatan}

Alat-alat yang digunakan dalam penelitian ini adalah oven, $\mathrm{pH}$ meter, lumpang dan alu, ayakan 100 mesh, Hemogenizer Eyela NZ, peralatan gelas yang umum di gunakan dalam laboratorium dan spektrofotometer UVVis.

Bahan dasar yang digunakan dalam penelitian ini adalah kulit pisang kepok (kulit berwarna kuning), zat warna
Rhodamin B, kertas saring Whatman No.41, dan akuades.

\section{Rancangan Penelitian}

Rancangan yang di gunakan dalam penelitian ini yaitu menggunakan Rancangan Acak Lengkap (RAL). Variabel pertama yang diterapkan dalam penelitian ini yaitu Penentuan waktu kontak dengan variasi waktu : 10, 30, 60, 90, dan 120 menit. Variabel ke dua variasi konsentrasi terdiri dari lima taraf yaitu : 2, 4, 6, 8, dan 10 ppm. Setiap perlakuan diulang dua kali.

\section{Prosedur Kerja}

\section{Penyiapan sampel (Pratiwi, 2014)}

Kulit buah pisang kepok terlebih dahulu dicuci untuk menghilangkan pengotor yang melekat pada kulit pisang tersebut hingga bersih. Setelah itu kulit buah pisang dikeringkan dalam oven pada temperatur $80{ }^{\circ} \mathrm{C}$ sampai beratnya konstan. Selanjutnya kulit pisang dihancurkan dan diayak menggunakan ayakan 100 mesh.

Penentuan panjang gelombang maksimum ( $\left.\lambda_{\text {maks }}\right)$ (Kurniasih et al., 2014)

Larutan Rhodamin B 5 mg/L diukur absorbansinya pada panjang gelombang 400-700 nm dengan spektrofotometer UVVis. Panjang gelombang yang menghasilkan absorbansi maksimum merupakan $\lambda_{\text {maks }}$ dari rhodamin $B$.

Pembuatan Larutan Standar Rhodamin B Pembuatan larutan standar Rhodamin B dilakukan dengan cara, Rhodamin B sebanyak 100 mg dilarutkan 
dalam $1 \mathrm{~L}$ akuades dengan konsentrasi 100 ppm, sebagai larutan induk. Larutan standar selanjutnya dibuat dari larutan induk dengan konsentrasi 0,25 ppm, 0,5 ppm, 1 ppm, 2 ppm dan 4 ppm. Selanjutnya absorbansi larutan pada panjang gelombang maksimum yang telah diperoleh diplot terhadap konsentrasi untuk mendapatkan kurva standar.

Penentuan waktu kontak kulit pisang
terhadap adsorpsi Rhodamin B (Pratiwi, 2014 dan Dyah, 2015)

Larutan rhodamin B diambil sebanyak $25 \mathrm{~mL}$ dengan konsentrasi 6 ppm dimasukkan ke dalam gelas kimia $100 \mathrm{~mL}$ dan ditambahkan $0,1 \mathrm{~g}$ tepung kulit pisang larutan diaduk menggunakan Homogenizer selama variasi waktu 10, 30, 60, 90, dan 120 menit dengan kecepatan 60 rpm. Larutan disaring menggunakan whatman No.41 dan filtratnya diukur dengan spektrofotometer UV -Vis.

Penentuan konsentrasi optimum kulit pisang kepok terhadap zat warna rhodamin B (Dyah, 2015)

Larutan rhodamin B diambil sebanyak $25 \mathrm{~mL}$ dengan variasi konsentrasi yaitu 2 , 4, 6, 8, dan 10 ppm dimasukkan ke dalam gelas kimia $100 \mathrm{~mL}$. Kemudian di tambahkan 0,1 g tepung kulit pisang selanjutnya diaduk menggunakan homogenizer berdasarkan waktu terbaik yang diperoleh sebelumnya dengan kecepatan $60 \mathrm{rpm}$. Larutan selanjutnya disaring menggunakan whatman N0.41 dan filtratnya diukur menggunakan spektrofotometer UV-Vis.

\section{Penentuan Kapasitas Adsorpsi}

Kapasitas adsorpsi dihitung menggunakan persamaan :

$$
Q=\frac{\left(C_{o}-C\right) x V}{W}
$$

dimana : $Q=$ Daya adsorpsi $(\mathrm{mg} / \mathrm{g})$

$\mathrm{W}=$ Berat biosorben $(\mathrm{g})$

$\mathrm{C}_{0}=$ Konsentrasi awal Rhodamin $\mathrm{B}(\mathrm{mg} / \mathrm{L})$

$C=$ Konsentrasi Rhodamin $B$ sisa dalam filtrat $(\mathrm{mg} / \mathrm{L}$ )

$\mathrm{V}=$ Volume Larutan Rhodamin $\mathrm{B}(\mathrm{ml})$

\section{Penentuan \% Penjerapan}

$$
\% \text { penjerapan }=\frac{\mathrm{Ct}}{\mathrm{Co}} \times 100 \%
$$

dimana :

$\mathrm{C}_{\mathrm{t}}=$ Konsentrasi terserap Rhodamin B $(\mathrm{mg} / \mathrm{L})$

$\mathrm{C}_{0}=$ Konsentrasi awal Rhodamin B ( $\left.\mathrm{mg} / \mathrm{L}\right)$

\section{HASIL DAN PEMBAHASAN}

\section{Adsorpsi Kulit Pisang Kepok Terhadap Zat Warna Rhodamin B Pada Berbagai Variasi Waktu}

Kecepatan adsorpsi dipengaruhi oleh difusi film atau difusi pori yang tergantung pada kecepatan pengocokan dalam sistem. Difusi pori umumnya mencapai optimum bila kontak sistem terjadi dengan pengocokan yang kuat (Rosyidah, 2008). Penelitian ini dilakukan untuk melihat pengaruh waktu kontak terhadap proses adsorpsi, dengan cara variasi waktu kontak mulai dari 10, 30, 60, 90, dan 120 menit menggunakan homogenizer dengan kecepatan $60 \mathrm{rpm}$. 


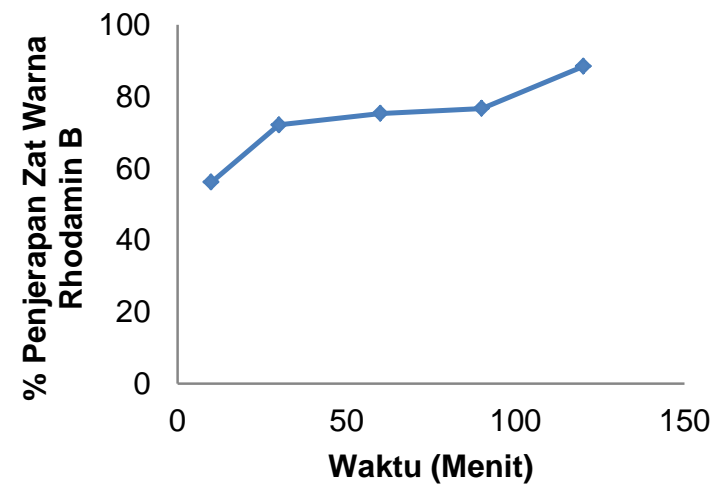

Gambar 1 Grafik hubungan antara waktu kontak terhadap persentase penjerapan (\%) Zat Warna Rhodamin B

Semakin lama waktu kontak antara adsorbat dengan adsorben, maka semakin banyak pula jumlah zat warna rhodamin B yang terserap per gram biosorben (Gambar 1). Waktu kontak merupakan suatu hal yang sangat menentukan dalam proses adsorpsi. Dari grafik dapat diketahui bahwa pada waktu kontak selama 10 menit sampai 120 menit terjadi kenaikan adsorpsi. Hal ini dikarenakan semakin lama waktu kontak semakin banyak partikel - partikel bubuk kulit pisang kepok yang bertumbukan dan berinteraksi dengan larutan Rhodamin B sehingga kemampuan adsorpsinya meningkat.

Hasil analisis sidik ragam menggunakan SPSS 20 dengan taraf kepercayaan 95\% ditunjukkan pada table ANOVA dengan nilai signifikan $(0,00)<$ 0,05 (a) yang menunjukkan ada pengaruh antara waktu kontak terhadap persentase penjerapan (\%) Zat Warna Rhodamin B. Berdasarkan hasil uji lanjut Duncan dengan taraf kepercayaan 95\% perbedaan tiap kelompok dapat dilihat dari nilai harmonic mean yang dihasilkan tiap kelompok berada dalam kolom subset yang sama atau berbeda. Pada hasil uji menunjukkan bahwa persentase penjerapan pada waktu kontak 10 menit dengan waktu 30, 60, dan 90 menit berbeda nyata, pada waktu kontak 30,60, dan 90 menit tidak berbeda nyata, sedangkan konsentrasi 90 dan 120 menit berbeda nyata. Dengan demikian, pada waktu kontak 120 menit direkomendasikan untuk digunakan sebagai waktu untuk mengadsorpsi zat warna Rhodamin B.

\section{Pengaruh Konsentrasi Zat Warna Rhodamin B Terhadap Adsorpsi Kulit Pisang Kepok}

Kapasitas adsorpsi kulit pisang kepok terhadap zat warna Rhodamin B di tentukan dengan cara variasi konsentrasi larutan Rhodamin B mulai dari 2, 4, 6, 8, dan $10 \mathrm{ppm}$. Proses adsorpsi dilakukan pada waktu yaitu 120 menit. Adapun grafik hubungan antara konsentrasi awal larutan zat warna dengan jumlah zat warna yang teradsorpsi disajikan pada gambar 2.

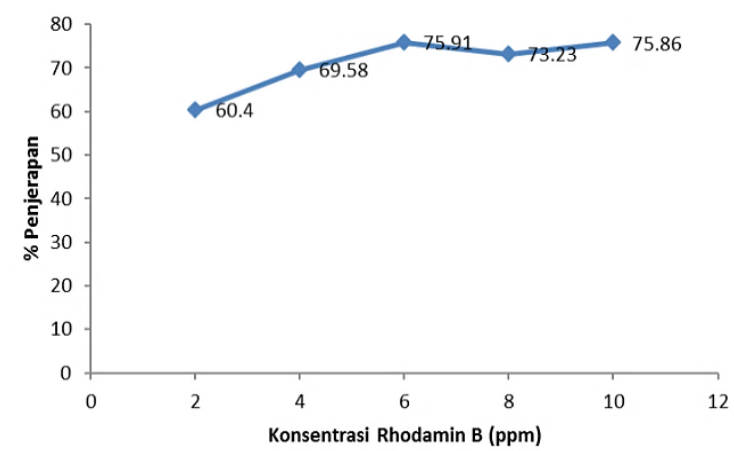

Gambar 2 Grafik hubungan antara konsentrasi terhadap persentase penjerapan (\%) Zat Warna Rhodamin B 
Terjadi penyerapan larutan Rhodamin B dari 2 ppm sampai 4 ppm dan mencapai nilai yang statis pada konsentrasi 6 ppm (Gambar 2). Hal ini dikarenakan semakin besar konsentrasi larutan Rhodamin B maka semakin banyak partikel - partikel bubuk kulit pisang kepok yang bertumbukan dan berinteraksi dengan Rhodamin B, sehingga kemampuan adsorpsinya meningkat. Ikatan yang terjadi antara ion adsorbat dengan gugus $(-\mathrm{OH})$ pada polisakarida ini dapat terjadi melalui ikatan hidrogen dan gaya Van der Walls. Polisakarida mempunyai potensi yang cukup besar untuk dijadikan sebagai penyerap karena gugus $-\mathrm{OH}$ yang terikat dapat berinteraksi dengan komponen adsorbat. Keberadaan gugus $-\mathrm{OH}$ pada polisakarida menyumbang polaritas pada polimer tersebut. Dengan demikian polisakarida akan lebih menyerap senyawa yang bersifat polar dibandingkan yang kurang polar (Kurniadi, 2010).

Konsentrasi maksimum Rhodamin B terjadi pada konsentrasi 6 ppm dengan kapasitas adsorpsi sebesar 4,55 mg/g. Pada keadaan ini, kapasitas adsorpsi permukaan adsorben kulit pisang telah jenuh dan mengalami kesetimbangan antara konsentrasi dalam adsorben kulit pisang dengan lingkungannya sehingga penyerapan pada konsentrasi 10 ppm menjadi konstan atau hampir sama. Hasil penelitian ini menunjukkan bahwa persentasi penjerapan kulit pisang kepok terhadap zat warna Rhodamin B lebih tinggi dibandingkan dengan penelitian sebelumnya oleh Novitasari et al. (2013) yaitu sebesar 1,762 mg / g. Perbedaan ini disebabkan karena adanya perbedaan kandungan selulosa pada jenis adsorben yang digunakan. Novitasari et al. (2013) menggunakan adsoben serat daun nanas untuk mengadsorpsi zat warna tekstil Rhodamin B.

Hasil analisis sidik ragam menggunakan SPSS 20 dengan taraf kepercayaan $95 \%$ di tunjukkan pada table ANOVA dengan nilai signifikan $(0,00)$ 0,05 (a) atau konsentrasi zat warna berpengaruh nyata terhadap persentase penjerapan (\%) Zat Warna Rhodamin B. Hasil uji lanjut Duncan dengan taraf kepercayaan 95\% menunjukkan bahwa persentase penjerapan pada konsentrasi 2 ppm, 4 ppm, dan 8 ppm berbeda nyata, Hal ini disebabkan karena pada konsentrasi yang diteliti adsorben belum terlalu banyak berikatan dengan zat warna atau adsorben belum jenuh dalam hal ini belum mencapai kesetimbangan antara konsentrasi dalam adsorben kulit pisang, sedangkan pada konsentrasi 6 ppm dan 10 ppm berbeda tidak nyata.

\section{KESIMPULAN}

Adsorpsi zat warna Rhodamin B oleh kulit pisang kepok mencapai maksimum pada waktu 120 menit. Sedangkan konsentrasi maksimum larutan Rhodamin B 6 ppm dengan kapasitas adsorpsi sebesar 4,55 mg Rhodamin B/g adsorben. 


\section{DAFTAR PUSTAKA}

Annadurai, G., R.S. Juang., D.J. Lee. 2002. Use of cellulose-based wastes for adsorption of dyes from aqueous solutions. Journal of Hazardous Materials, B92: 263-274.

Dyah, F., Dwita Oktiarni., dan Lusiana. 2015. Pemanfaatan Kulit Pisang Sebagai Adsorben Zat Warna Methylene Blue. Gradien, 11(2).

Khan, T., Amin, M. dan Chaudhuri, M. 2011. Banana Peel : A Low-Cost Adsorbent for Removal of Reactive Dye from Aqueous Solution. Proceedings International Conference on Civil, Offshore and Environmental Engineering University Teknologi Petronas.

Kurniadi, Tedi. 2010. Kopolimerisasi Grafting Monomer Asam Akrilat pada Onggok Singkong dan Karakteristiknya. Tesis. Bogor : Institut Pertanian Bogor.

Kurniasih, M., Riapanitra, A., Rohadi, A. 2014. Adsorpsi Rhodamin B dengan Adsorben Kitosan Serbuk dan Beads Kitosan. Sains \& Maematika, 2(2).

Novitasari dan Budi Utami. 2013. Pemanfaatan Serat Daun Nanas (Ananas cosmosus) Sebagai adsorben zat warna tekstil Rhodamin B. Prosiding Seminar Nasional Kimia Dan Pendidikan Kimia V. 6 April 2013. Suarakarta: FKIP. Universitas Sebeleas Maret.

Pankaj, Tanwar, B., Ghoyal, S., dan Patnala, P.K. 2012. A comparative Study of Sonosorption of Reactive Red 141 Dye on $\mathrm{TiO}_{2}$, Banana Peel, Orange Peel and Hardwood Saw Dust. J. Applicable Chemistry, 1(4) : 505-511

Pratiwi, W. 2014. Pemanfaatan Limbah Kulit Pisang Kepok (Musa paradisiacal formatypica) Sebagai Biosorben Logam Merkuri (Hg). Skripsi. Palu: Program Studi Kimia Fakultas MIPA, Universitas Tadulako.

Rosyidah, Halimatur. 2008. Studi Kinetika Adsorpsi Merkuri (II) Pada Biomassa Daun Enceng Gondok (Eichhornia crassipes) Yang Diimobilisasi Pada Matriks Polisilikat. Skripsi. Malang: Universitas Islam Negeri Malang.

Syah, D., Utama, S., Mahrus, Z. 2005. Manfaat dan Bahaya Bahan Tambahan Pangan. Bogor: Himpunan Alumni Fakultas Teknologi Pertanian IPB.

Wijaya, K., Eko S., Is Fatimah, Sri S., dan Diyan K. 2006. Utilisasi $\mathrm{TiO}_{2}-$ Zeolit dan Sinar UV untuk Fotodegradasi Zat warna Congo Red, TEKNOIN , 11(3): 199-209. 